\title{
Particles of Coffee Wastes as Reinforcement in Polyhydroxybutyrate (PHB) Based Composites
}

\author{
Kelen Cristina Reis ${ }^{a *}$, Lucinéia Pereira ${ }^{b}$, Isabel Cristina Nogueira Alves Melo ${ }^{c}$, \\ José Manoel Marconcinid, Paulo Fernando Trugilhoc, Gustavo Henrique Denzin Tonolic \\ ${ }^{a}$ Programa de Pós-Graduação em Engenharia de Biomateriais, Departamento de Ciências Florestais, \\ Universidade Federal de Lavras - UFLA, CP 3037, CEP 37200-000, Lavras, MG, Brazil \\ ${ }^{b}$ Departamento de Química, Universidade Federal de Minas Gerais - UFMG, Belo Horizonte, MG, Brazil \\ 'Departamento de Ciências Florestais, Universidade Federal de Lavras - UFLA, \\ CP 3037, CEP 37200-000, Lavras, MG, Brazil \\ ${ }^{d}$ Laboratório Nacional de Nanotecnologia para o Agronegócio - LNNA, Embrapa \\ Instrumentação - CNPDIA, CP 741, CEP 13560-970, São Carlos, SP, Brazil
}

Received: August 18, 2014; Revised: May 17, 2015

\begin{abstract}
The objective of the present study was to evaluate lignocellulosic particles from sub-products of the coffee industry (coffee parchment - $\mathrm{CP}$ and husk - $\mathrm{CH}$ ) into polyhydroxybutyrate (PHB) as a promising reinforcing filler in the biocomposites. The effects of type $(\mathrm{CP}$ or $\mathrm{CH})$ and content (neat, $10 \%$ and $20 \%$ ) of coffee wastes on the thermal, mechanical, microstructural and physical properties of the ensuing composites were evaluated. Thermal stability of the composites was improved by the coffee residues at different contents, while degree of crystallinity was decreased with the inclusion of CP. The addition of $10 \%$ of $\mathrm{CP}$ has not influenced significantly the tensile strength (TS) and Izod strength (IS), in relation to the neat PHB. Tensile strength (TS), MOE and Izod strength (IS) of the composites have increased significantly with the inclusion of $20 \%$ of CP. The increase in the content of coffee waste particles increased the water absorption of the composites.
\end{abstract}

Keywords: coffee residues, biopolymer, biocomposite, extrusion, injection

\section{Introduction}

The need for materials that are biodegradable and have appropriate characteristics for specific purposes is ever increasing due to the lack of resources and increasing levels of environmental pollution. Thus, several researches are proceeding to develop composites using various recycled wastes $^{1,2}$, especially environmental friendly agro-wastes (lignocellulosic materials) as reinforcing fillers and thermoplastic polymers as matrix. Lignocellulosic materials are widely available from annual plants in most developing countries. They present several interesting advantages, particularly their low density, high specific stiffness and strength, biodegradability, their renewable character, their low processing energy in the case of chopped natural fibers, and their availability everywhere at modest cost and in a variety of morphologies and dimensions. All these properties make them convenient materials for matrix reinforcement, such as polymer composites, as witnesses the significant number of recent reviews and publications ${ }^{3-9}$.

Coffee (Coffea sp.) is one of the most important agricultural commodities in the world, and Brazil is the largest producer ${ }^{10}$. The coffee husk is the residue of the coffee bean extraction and is constituted of carbohydrates, proteins, minerals and approximately $30 \%$ of cellulose fibers. The parchment is a fibrous endocarp that surrounds and

*e-mail: kelen_cr@yahoo.com.br separates the coffee beans, and is constituted of about $49 \%$ of cellulose ${ }^{11}$. There is scarce information in the literature about the use of coffee residues as filler in plastics. Just a previous work $^{12}$ tested $\mathrm{PHB} / \mathrm{HV}$ composites prepared by casting reinforced with coffee wastes and showed some increment in the mechanical properties. Therefore, further investigation is merited in order to target the scarcity of knowledge on this topic. The convenience of the bio-based composites lies in the fact that the ingredients are obtained easily from vegetable wastes and hence the composites can be used to resolve environmental problems and to manufacture products with various physical properties and effective functions. Lignocellulosic materials can be used as alternative to the inorganic and synthetic fibers normally used as reinforcing fillers in plastics. Then, at the end of their life they can be easily naturally decomposed without harming the environment. They are a renewable resource with production requiring little energy and carbon dioxide neutral, i.e. they do not return excess carbon dioxide into the atmosphere when they are composted or combusted ${ }^{13}$.

Polyhydroxybutyrate - PHB is biodegradable thermoplastic polyester produced by bacterial fermentation, whose biodegradation time is considered short compared with traditional polymers resultant from petroleum, which are not biodegradable. PHB has high potential for industrial applications due to its high crystallinity (50-70\%), excellent 
gas barrier (water vapor permeability around $560 \mathrm{~g} . \mu \mathrm{m} / \mathrm{m}^{2} /$ day) and physical properties similar to those of polypropylene $\mathrm{e}^{14}$. PHB has elastic modulus and tensile strength in the range of 2-13 GPa and 15-50 MPa respectively ${ }^{6,15,16}$. However, the use of PHB is limited because of its thermal instability, excessive brittleness, and high production cost compared with plastics from petroleum ${ }^{17}$. Incorporating lignocellulosic particles into PHB is expected to be a cost-effective and promising solution to improve mechanical properties and thermal stability of these composites. The incorporation of lignocellulosics can also behave as a nucleating agent during the crystallization and interfere on their supermolecular structure $^{18,19}$. Therefore, the present study aims to evaluate lignocellulosic particles from coffee industry sub-products (coffee parchment - $\mathrm{CP}$ and husk - $\mathrm{CH}$ ) into polyhydroxybutyrate (PHB) as promising reinforcing filler in the biocomposites. The effects of type (CP or $\mathrm{CH}$ ) and content (neat, $10 \%$ and $20 \%$ ) of coffee wastes on the mechanical, physical, thermal and microstructural properties of the ensuing composites were evaluated.

\section{Experimental}

\subsection{Materials}

Coffee parchment $(\mathrm{CP})$ and coffee husk $(\mathrm{CH})$ were previously oven dried at $80{ }^{\circ} \mathrm{C}$ for $24 \mathrm{~h}$ and milled (Tecnal TE 650, Brasil). The particle sizes of $\mathrm{CP}$ and $\mathrm{CH}$ used were that retained in the screens of 60 and 80 mesh respectively ${ }^{20}$. The $\mathrm{CP}$ and $\mathrm{CH}$ were used without any subsequent treatment. PHB (Biocycle ${ }^{\circledR}$ ) was obtained from PHB Industrial S/A, Brazil, in white powder form. This polymer is produced from sugarcane by microorganisms of the Alcaligenes $s p$. species. The PHB presents density of $1.2 \mathrm{~g} / \mathrm{mL}$ and a melt flow index of $10.8 \mathrm{~g} / 10 \mathrm{~min}$. No plasticizer or other additive was used for $\mathrm{PHB}$ processing. Typical properties of the PHB used are: tensile strength of $36 \mathrm{MPa}$ and melting point of $165-170{ }^{\circ} \mathrm{C}$.

\subsection{Production of the composites}

Compounding mixtures with $0 \%, 10 \%$ and $20 \%$ (by mass) of coffee parchment $(\mathrm{PHB}+\mathrm{CP})$ and coffee husk $(\mathrm{PHB}+\mathrm{CH})$ were produced by extrusion. The mixtures were extruded in a co-rotatory twin-screw extruder (Imacom model DRC 30:40 IF). The processing conditions are presented in Table 1. After compounding, all the compositions were pelletized in a Jethro pelletizer. To improve the pelletization procedure, the extruded materials were allowed to rest for thirty days to enhance their crystallinity ${ }^{21}$.

The neat $\mathrm{PHB}, \mathrm{PHB}+\mathrm{CP}$ and $\mathrm{PHB}+\mathrm{CH}$ composites were then injected in an Arburg ${ }^{\circledR}$ Allrounder 270V 300-120 injector, using an ASTM 638-03 ${ }^{[22]}$ specimen tests injection mold for tensile and ASTM 256-05 ${ }^{[23]}$ for impact tests. The conditions employed for the injection of the $\mathrm{PHB}, \mathrm{PHB}+\mathrm{CP}$ and $\mathrm{PHB}+\mathrm{CH}$ composites are described in Table 1 .

\subsection{Composite characterization}

Limit of proportionality (LOP), tensile strength (TS) and modulus of elasticity (MOE) of the composites were determined in a universal testing machine following the procedures of ASTM D638-03 ${ }^{[24]}$. The limit of proportionality (LOP) was described as the stress corresponding to the upper point of the linear portion of the stress-strain curve and it is related to the point where the first crack happens in the composite, i.e. the first crack strength. Specific energy (SE) was defined as the energy absorbed during the tensile test divided by the cross-sectional area of the specimen under investigation. The absorbed energy was obtained by integration of the area below the load versus deflection curve at the point corresponding to a reduction in load carrying capacity to $10 \%$ of the maximum reached. Izod impact test was performed in a Tinius Olsen Impact 104 according the procedures of $\mathrm{ASTM}^{\circledR} \mathrm{D} 256-05^{[25]}$.

The composites were subjected to thermogravimetric analysis (TG) in a DTG Shimadzu 60AH. Samples of around $10 \mathrm{mg}$ were heated in a Tin crucible from 25 to $600{ }^{\circ} \mathrm{C}$ in nitrogen flowing at $50 \mathrm{~mL} / \mathrm{min}$. The heating rate was $10{ }^{\circ} \mathrm{C} / \mathrm{min}$. The critical weight loss temperatures $\left(\mathrm{T}_{\text {onset }}\right)$ were obtained from the onset points of the TG curves, and this was represented by the intersection of the extrapoling line, at the beginning of the thermal event, with the tangent of the curve in the thermal event ${ }^{26}$.

The differential scanning calorimetry (DSC) was performed in a Shimadzu DSC 60 AH instrument; approximately $2 \mathrm{mg}$ of sample was placed in an aluminum crucible, which was heated from room temperature $\left(25^{\circ} \mathrm{C}\right)$ to $550{ }^{\circ} \mathrm{C}$ at a heating rate of $10^{\circ} \mathrm{C} / \mathrm{min}$ and constant flow of nitrogen of $50 \mathrm{~mL} / \mathrm{min}$. From the analysis of DSC was obtained the melting temperature (Tm) of the composites. The degree of crystallinity $(\mathrm{Xc})$ of the PHB composites was estimated

Table 1. Extrusion and injection conditions for neat PHB and its composites with coffee wastes (coffee parchment - CP and husk - CH).

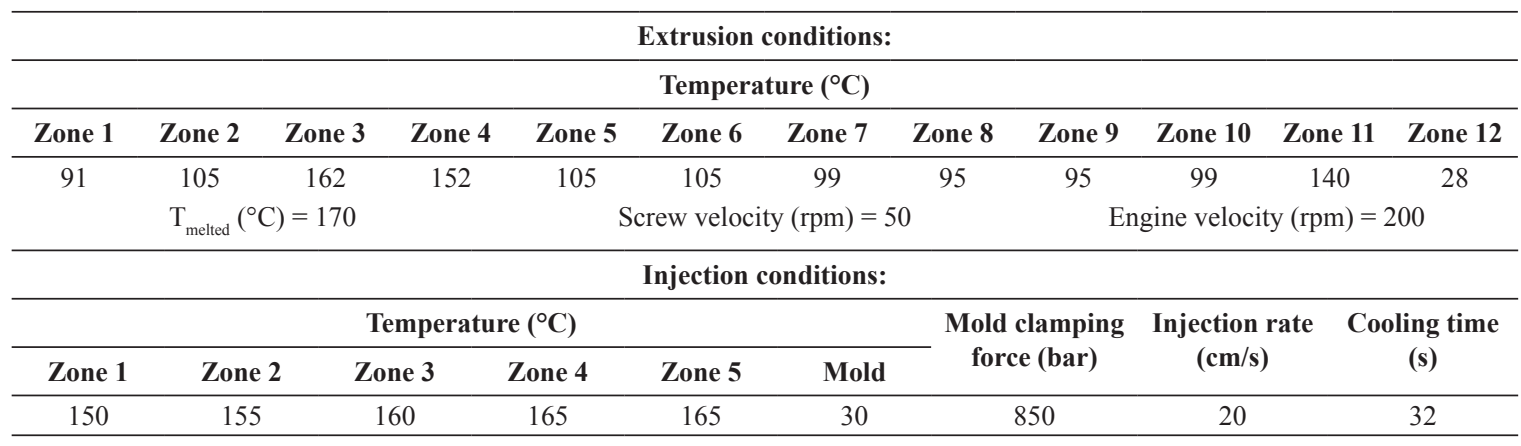


using the enthalpy of fusion of the sample, as reported in Thiré et al. ${ }^{27}$.

Scanning electron microscopy (SEM) with secondary electron (SE) detector, operated at $20 \mathrm{kV}$ accelerating voltage, was used to visualize the fractured surfaces of the neat PHB and composites after the tensile text. Fractured surfaces were gold coated in a Bal-Tec SCD050 coating system before being analyzed in a Zeiss LEO Evo 40 microscope.

The evaluation of water absorption and stability of the composites was determined according to ASTM D570 ${ }^{[28]}$. The stability of the composites was determined by the mass loss during the test period. For evaluation of the water absorption, the samples were first dried at $65^{\circ} \mathrm{C}$ for $4 \mathrm{~h}$ before being immersed in distilled water. The degree of water absorption was determined on the average of three specimens and the results expressed as a percentage. This test was carried out for seven weeks.

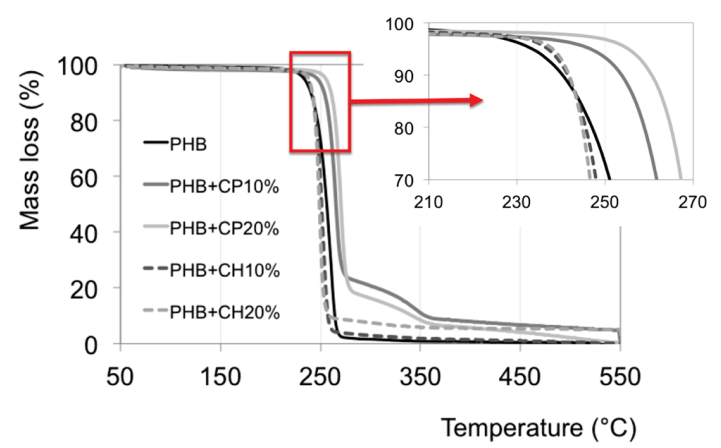

(a)

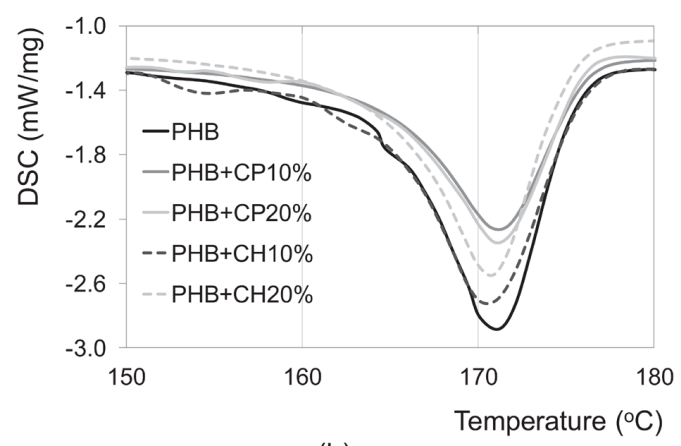

(b)

Figure 1. TGA and DSC curves of the neat PHB and PHB composites with different contents of coffee pulp particles $(\mathrm{PHB}+\mathrm{CP})$ and coffee husk particles $(\mathrm{PHB}+\mathrm{CH})$.

\section{Results and Discussion}

\subsection{Thermal analysis}

The inclusion of CP particles increased the onset degradation temperature $\left(\mathrm{T}_{\text {onset }}\right)$ of the composites (Figure 1a and Table 2), as also observed elsewhere by Melo et al. ${ }^{29}$ for composites with carnauba fibers. This is because of the higher thermal stability of the lignocellulosic particles in relation to PHB. Thermal analysis (TG) of the composites showed one main thermal degradation stage at temperatures of $230-270{ }^{\circ} \mathrm{C}$, with mass loss of around $90 \%$ for neat $\mathrm{PHB}$ and $\mathrm{PHB}+\mathrm{CH}$ and $75-80 \%$ for $\mathrm{PHB}+\mathrm{CP}$. For neat $\mathrm{PHB}$ and all the composites, there is another loss of mass, between 270 and $700{ }^{\circ} \mathrm{C}$, due to residual organic matter and ashes. All these data agree with previous reported values ${ }^{30,31}$.

For the composites with $\mathrm{CP}$ the maximum rate of mass loss occurred at around $350^{\circ} \mathrm{C}$ probably due to the decomposition of hemicelluloses (normally in the range of $225-325^{\circ} \mathrm{C}$ ), residual lignin (in the range of $250-500^{\circ} \mathrm{C}$ ) and cellulose (in the range of $305-375^{\circ} \mathrm{C}$ ) as reported by Prins et al. ${ }^{32}$ and Melo et al. ${ }^{29}$. According to Pachekoskia et al. ${ }^{33}$ the thermal degradation of PHB is caused almost exclusively by a random scission on the ester bond at high temperatures (starting at $200^{\circ} \mathrm{C}$ ). Decomposition of the neat PHB occurred before the $\mathrm{PHB}$ composites with addition of the $\mathrm{CP}$ particles $(\mathrm{PHB}+\mathrm{CP})$. This observation may suggest that the use of CP particles improve thermal stability of PHB.

Figure $1 \mathrm{~b}$ shows the DSC thermograms of the neat $\mathrm{PHB}$ and its composites with coffee pulp $(\mathrm{PHB}+\mathrm{CP})$ and husks $(\mathrm{PHB}+\mathrm{CH})$. The temperature and intensity of the transitions are affected by the coffee residues at different contents. Values vary between studies depending on the preparation and storage conditions of the samples ${ }^{34}$. The Tm values of the neat PHB and composites are in agreement with those of Reis et al. ${ }^{35}$. The Tm of the composite depends on many factors such as morphology and size of the particles, kinetics of crystallization and compounding process ${ }^{36}$. The endothermic peaks, at around $170-172{ }^{\circ} \mathrm{C}$, can be observed for all the formulations. Furthermore, it can be noticed that at approximately $150^{\circ} \mathrm{C}$ the formulations begin to melt, which is completed at around $173{ }^{\circ} \mathrm{C}$. Complete coalescence or conglutination of the crystals in all the samples takes place at around $178^{\circ} \mathrm{C}$. It should also be noted that the enthalpy of fusion depends on the area under the DSC curve ${ }^{37}$ and is related with the calculated degree of crystallinity (Xc) of the samples, as presented in Table 2. The sample prepared with $\mathrm{CP}$ has a narrow fusion range and lower fusion enthalpy, which led to lower Xc. $\mathrm{CH}$ particles

Table 2. Thermal properties obtained from TG and DSC heating curves of second heating scan for neat PHB and its composites with coffee wastes (coffee parchment - $\mathrm{CP}$ and husk - $\mathrm{CH}$ ).

\begin{tabular}{ccccc}
\hline Sample & $\mathbf{T}_{\text {onset }}\left({ }^{\circ} \mathbf{C}\right)$ & $\mathbf{T m}\left({ }^{\circ} \mathbf{C}\right)$ & $\Delta \mathbf{H m}\left({ }^{\circ} \mathbf{C}\right)$ & $\mathbf{X c}(\%)$ \\
\hline PHB & 232 & 171.2 & 93.5 & 64.0 \\
PHB + CP10\% & 253 & 171.0 & 52.9 & 40.2 \\
PHB + CP20\% & 256 & 171.1 & 57.9 & 49.5 \\
PHB + CH $10 \%$ & 237 & 170.5 & 84.2 & 64.1 \\
\hline
\end{tabular}

$\mathrm{T}_{\text {onset }}=$ critical weight loss temperatures; $\mathrm{Tm}=$ melting temperature; $\Delta \mathrm{Hm}=$ enthalpy of fusion; $\mathrm{Xc}=$ degree of crystallinity. 
have not greatly affected Xc. The neat PHB sample presents a large peak with high fusion enthalpy ${ }^{38}$. The lower degree of crystallinity $(\mathrm{Xc})$ of the $\mathrm{PHB}+\mathrm{CP}$ composites suggest a less-perfect arrangement of the PHB polymer crystal structures as the CP particles are added to the PHB matrix. This may be related to a slight reduction in crystal size and lower Xc as a result of the restricted polymer chain mobility ${ }^{39,40}$ in the presence of the CP particles, which are very larger than the $\mathrm{CH}$ particles studies have shown that lignocellulosic particles act as a nucleating agent, promoting the formation of transcrystalline structures along particle surfaces during crystallization from the melt ${ }^{41}$. When PHB crystallizes in the presence of the particles, crystals could grow on the particle surfaces ${ }^{42}$. The reductions in overall polymer crystallinity are expected to have occurred from the introduction of discontinuities in the matrix crystal structure caused by the disordered growth of crystals at the particle-matrix interface ${ }^{43}$. The apparent double peak of the neat PHB melting endotherm suggests evidence of the formation of multiple morphological crystal structures and/or the phenomena of melt recrystallization that has been shown to occur during the melting process of the neat polymers ${ }^{44}$.

\subsection{Mechanical properties}

Figure 2 depicts the stress vs. strain curves of neat PHB and composites. Table 3 presents the average mechanical properties obtained during tensile and Izod impact tests. The addition of $10 \%$ of CP has not influenced significantly the tensile strength (TS) and Izod strength (IS), in relation to the neat PHB. Despite the slight decrease of TS, the MOE

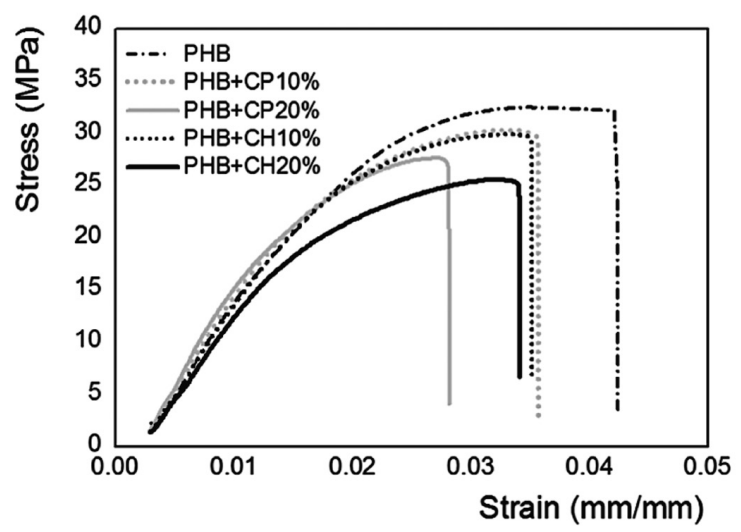

Figure 2. Stress vs. strain curves of the neat PHB and composites. and the IS of the composites have increased significantly with the inclusion of $20 \%$ of CP particles. This is probably due to the higher size (low contact area) and smooth surface of the CP particles, favoring poor anchoring to the matrix (as stated by the lower tensile strength in relation to neat PHB) and considerable incidence of pulled out particles (arrows 1 in Figure 3), as previously reported elsewhere for PHB composites reinforced with $44 \%$ (by mass) of flax fibers ${ }^{29}$. The high IS values for composites with $20 \%$ of CP is therefore the result of the frictional slip process during the pulling out of these CP particles. Contrarily, IS values decreased significantly by addition of $\mathrm{CH}$ particles. In this case, the fracture of the particles prevails over their pull out, since these latter are more adhered to the matrix as a consequence of the higher contact area (because they are smaller) of the $\mathrm{CH}$ particles. Garkhail et al. ${ }^{45}$ and Barkoula et al. ${ }^{46}$ also have not found improvements in the mechanical properties of PHB composites when using flax fibers as reinforcement. The addition of both coffee waste particles to PHB decreased the specific energy (SE) of the composites in relation to the neat PHB (Table 3 ). This is because the particles decrease the ductility of the PHB matrix when the inclusion of the particles leads to more defects in the specimens and could be also attributed to the formation of agglomerates, as shown by SEM micrographs in the next section. The reductions in TS and SE in the specimens with high particles content $(20 \%)$ are attributed to an embrittlement caused by improper particle wetting that resulted in a deficient particle-matrix interface. Pores and imperfections at the particles interface can induce fracture in highly crystalline polymers ${ }^{43,46}$. According to Wong et al. ${ }^{47}$, the crystallites in the matrix located away from the fiber show a reduction in size, which can contribute to the reduction of brittleness of the matrix in the sense that cracks were often observed when crystals were large.

\subsection{Microstructure of the composites}

The scanning electron microscopy provides information on the microstructure of the composites, and permits the observation of the interaction and dispersion of the particles on the polymer matrix. Micrographs of the fracture surface of the composites are shown in Figure 3 to 5. The fracture surface of the neat PHB specimens (Figure 3) appears homogeneous, compact and without visible voids and flaws. The fracture surfaces of both $\mathrm{PHB}+\mathrm{CP}$ composites (10 and $20 \%$ of CP) show that CP particles were pulled out from the PHB matrix (Figure 3 and 5), as a result of the less strong interaction between $\mathrm{CP}$ and PHB matrix. The increase of failures (voids and flaws) occurred as

Table 3. Average values and standard deviation of the mechanical properties of the neat PHB and composites in the different conditions.

\begin{tabular}{cccccc}
\hline Composites & LOP $(\mathbf{M P a})$ & TS $(\mathbf{M P a})$ & MOE $(\mathbf{G P a})$ & SE $\left(\mathbf{K J} / \mathbf{m}^{2}\right)$ & IS $(\mathbf{J} / \mathbf{m})$ \\
\hline PHB & $15.9 \pm 1.5$ & $31.9 \pm 0.9$ & $1.8 \pm 0.1$ & $73.4 \pm 7.1$ & $26.1 \pm 4.7$ \\
PHB + CP10\% & $14.4 \pm 1.8$ & $30.8 \pm 0.7$ & $1.9 \pm 0.1$ & $65.2 \pm 6.8$ & $26.8 \pm 2.7$ \\
PHB + CP20\% & $14.1 \pm 1.0$ & $27.7 \pm 0.5$ & $2.1 \pm 0.1$ & $44.1 \pm 4.5$ & $29.5 \pm 2.7$ \\
PHB + CH10\% & $14.7 \pm 1.3$ & $29.8 \pm 0.6$ & $1.7 \pm 0.1$ & $62.3 \pm 6.8$ & $20.3 \pm 2.6$ \\
PHB + CH20\% & $13.3 \pm 1.2$ & $26.1 \pm 1.2$ & $1.6 \pm 0.1$ & $50.5 \pm 9.0$ & $21.1 \pm 0.9$ \\
\hline
\end{tabular}

LOP: limit of proportionality; TS: tensile strength; MOE: modulus of elasticity; SE: specific energy; IS: Izod strength. 
particles concentration increases. In the composites with $20 \%$ of $\mathrm{CP}$, it can be observed that particles agglomerate and some pores were formed (arrow 2 in Figure 5). This is probably the explanation for the lower TS observed for the higher content of CP (Table 3). The fracture surface of the $\mathrm{PHB}+\mathrm{CH}$ composites is more homogeneous, showing the greater interaction of the $\mathrm{CH}$ particles with $\mathrm{PHB}$ matrix. The particles in the $\mathrm{PHB}+\mathrm{CH} 10 \%$ composites were not easily observed, while in the $\mathrm{PHB}+\mathrm{CH} 20 \%$ composites, the $\mathrm{CH}$ particles were observed in some agglomeration but more homogenously distributed in the matrix than others.

\subsection{Water absorption and mass loss}

Water absorption was significantly $(\mathrm{p}>0.05)$ influenced by the type and content of particles (Figure 6). The neat PHB specimens present lower water absorption than the $\mathrm{PHB}+\mathrm{CP}$ and $\mathrm{PHB}+\mathrm{CH}$ composites. Composites with $\mathrm{CH}$ particles absorb more water than those reinforced with $\mathrm{CP}$ particles. As already mentioned, the neat PHB specimens absorbed lower water than the particle reinforced composites, since the former is hydrophobic ${ }^{47}$. The water absorption

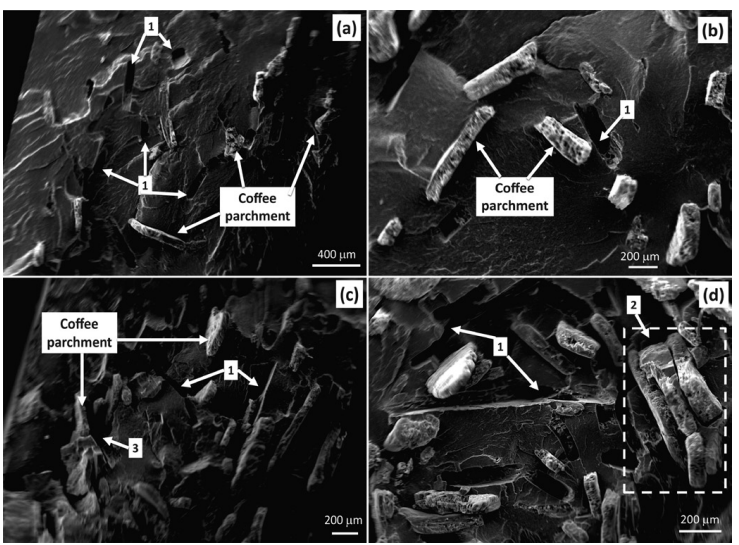

Figure 3. SEM micrographs of the fracture surface of the PHB composites reinforced with: (a,b) $10 \%$ of coffee parchment (CP); and (c,d) $20 \%$ of coffee parchment (CP). Arrows 1 show the spaces left by the pulled-out parchment particles. Arrows 2 and 3 show the agglomeration of the parchment particles and the defects due to particle agglomeration, respectively.

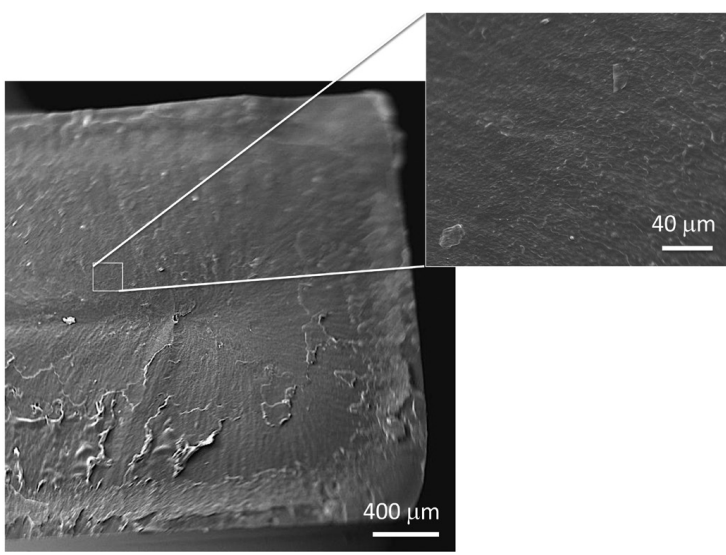

Figure 4. SEM micrographs of the fracture surface of the neat PHB (after injection). of the neat PHB was practically constant throughout the evaluated period. As expected, the increase in the content of both coffee waste particles increased the water absorption of the composite. This is due to voids (arrows 3 in Figure $3 \mathrm{c}$ and $5 \mathrm{~d}$ ) formed with the agglomeration of the particles into the matrix (arrows 2 in Figure 3d and 5c), as enforced by observations with SEM of the cross section of the fractured composite.

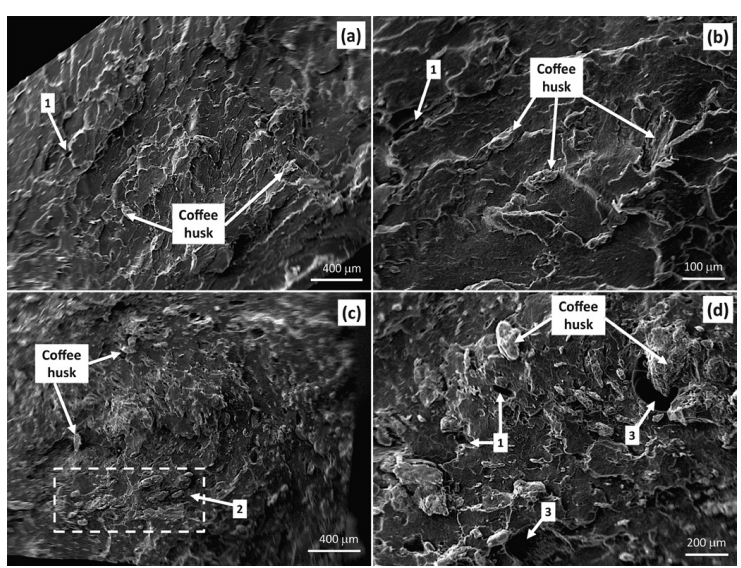

Figure 5. SEM micrographs of the fracture surface of the PHB composites reinforced with: $(\mathrm{a}, \mathrm{b}) 10 \%$ of coffee husk $(\mathrm{CH})$; and (c,d) $20 \%$ of coffee husk $(\mathrm{CH})$. Arrows 1 show the spaces left by the pulled-out husk particles. Arrows 2 and 3 show the agglomeration of the parchment particles and the defects due to particle agglomeration, respectively.

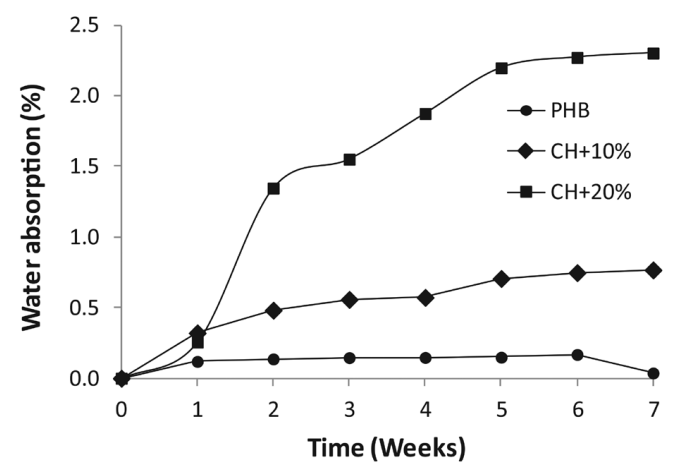

(a)

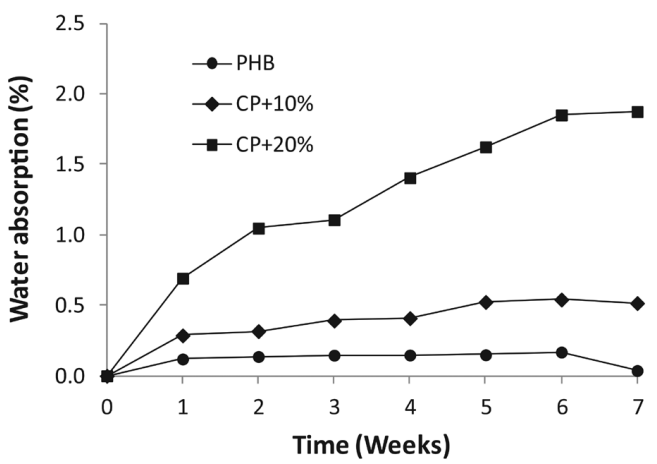

(b)

Figure 6. Water absorption in function of time: a) $\mathrm{PHB}+\mathrm{CH}$ and (b) $\mathrm{PHB}+\mathrm{CP}$ composites. 


\section{Conclusion}

The present study evaluated lignocellulosic particles from sub-products of the coffee industry (coffee parchment - CP and husk - $\mathrm{CH}$ ) as reinforcing filler in PHB biocomposites. The inclusion of $\mathrm{CP}$ and $\mathrm{CH}$ particles increased the onset degradation temperature $\left(\mathrm{T}_{\text {onset }}\right)$ of the composites. Thermal analysis (TG) of the composites showed one main thermal degradation stage at temperatures of $230-270^{\circ} \mathrm{C}$, with mass loss of around $90 \%$ for neat $\mathrm{PHB}$ and $\mathrm{PHB}+\mathrm{CH}$ and $75-80 \%$ for $\mathrm{PHB}+\mathrm{CP}$. The lower degree of crystallinity $(\mathrm{Xc})$ of the $\mathrm{PHB}+\mathrm{CP}$ composites suggest a less-perfect arrangement of the $\mathrm{PHB}$ polymer crystal structures as the $\mathrm{CP}$ particles are added to the PHB matrix. The addition of $10 \%$ of CP has not influenced significantly the TS and IS values, in relation to the neat PHB. Tensile strength (TS), MOE and Izod strength (IS) of the composites have increased significantly with the

\section{References}

1. Son JI, Kim HJ and Lee PW. Role of paper sludge particle size and extrusion temperature onperformance of paper sludgethermoplastic polymer composites. Journal of Applied Polymer Science. 2001; 82(11):2709-2718. http://dx.doi.org/10.1002/ app. 2123.

2. Son JI, Yang HS and Kim HJ. Physico-mechanical properties of paper sludge-thermoplastic polymer composites. Journal of Thermoplastic Composite Materials. 2004; 17(6):509-522. http://dx.doi.org/10.1177/0892705704038471.

3. Belgacem MN and Gandini A. Monomers, polymers and composites from renewable resources. Elsevier; 2008.

4. Sabu T and Pothan L. Cellulose fibre reinforced polymer composites. Philadelphia: Old City Publishing; 2008.

5. Campos A, Tonoli GHD, Marconcini JM, Mattoso LHC, Klamczynski A, Gregorski KS, et al. TPS/PCL composite reinforced with treated sisal fibers: property, biodegradation and water-absorption. Journal of Polymers and of Environment. 2013; 21(1):1-7. http://dx.doi.org/10.1007/s10924-012-0512-8.

6. Angelini S, Cerruti P, Immirzi B, Santagata G, Scarinzi G and Malinconico M. From biowaste to bioresource: Effect of a lignocellulosic filler on the properties of poly(3-hydroxybutyrate). International Journal of Biological Macromolecules. 2014; 71:163-173. http://dx.doi.org/10.1016/j.ijbiomac.2014.07.038. PMid:25086181.

7. Priya B, Gupta VK, Pathania D and Singha AS. Synthesis, characterization and antibacterial activity of biodegradable starch/PVA composite films reinforced with cellulosic fibre. Carbohydrate Polymers. 2014; 109(30):171-179. http://dx.doi. org/10.1016/j.carbpol.2014.03.044. PMid:24815414.

8. Naghmouchi I, Espinach FX, Mutjé P and Boufi S. Polypropylene composites based on lignocellulosic fillers: how the filler morphology affects the composite properties. Materials \& Design. 2015; 65:454-461. http://dx.doi.org/10.1016/j. matdes.2014.09.047.

9. Rosa SML, Santos EF, Ferreira CA and Nachtigall SMB. Studies on the properties of rice-husk-filled-PP composites: effect of maleated PP. Materials Research. 2009; 12(3):333-338. http:// dx.doi.org/10.1590/S1516-14392009000300014.

10. Pandey A, Soccol CR, Nigam P, Brand D, Mohan R and Roussos S. Biotechnological potential of coffee pulp and coffee husk for bioprocesses. Journal of Biochemistry Engineering. 2000; inclusion of $20 \%$ of CP. The increase in the content of both coffee waste particles increased the water absorption of the composite. The present work contributes to the scarcity of information about use of coffee residues to engineer polymeric composites for myriad applications.

\section{Acknowledgements}

The authors would like to thank FAPEMIG, FAPESP, CAPES and CNPq (Brazil) for their financial support. We are also indebted with PHB Industrial S/A for supplying the PHB and with Prof. Dr. Agnelli, Biodegradable Polymer Laboratory (Biocycle) - UFSCAR, for the supporting in the samples processing. Thanks also to PGCTM (UFLA), LME (UFLA) and Brazilian Research Network in Lignocellulosic Composites and Nanocomposites - RELIGAR.

6(2):153-162. http://dx.doi.org/10.1016/S1369-703X(00)00084-X PMid:10959086.

11. Esquivel P and Jiménez VM. Functional properties of coffee and coffee by-products. Food Research International. 2012; 46(2):488-495. http://dx.doi.org/10.1016/j.foodres.2011.05.028.

12. Machado ART, Martins PFQ, Fonseca EMB and Reis KC. Compósitos biodegradáveis a base de polihidroxibutiratohidroxivalerato (PHB-HV) reforçados com resíduos do beneficiamento do café. Revista Matéria. 2010; 15(3):400-404. http://dx.doi.org/10.1590/S1517-70762010000300002.

13. Yang H-S, Kim H-J, Son J, Park H-J, Lee B-J and Hwang T-S. Rice-husk flour filled polypropylene composites; mechanicaland morphological study. Composite Structures. 2004; 63(3-4):305312. http://dx.doi.org/10.1016/S0263-8223(03)00179-X.

14. Sharma R and Ray AR. Polyhydroxybutyrate, its copolymers and blends. Journal of Macromolecular Science - Rev. Macromolecular Chemistry and Physics. 1995; 35(2):327-359. http://dx.doi.org/10.1080/15321799508009640.

15. Modi S, Koelling K and Vodovotz Y. Assessment of PHB with varying hydroxyvalerate content for potential packaging applications. European Polymer Journal. 2011; 47(2):179-186. http://dx.doi.org/10.1016/j.eurpolymj.2010.11.010.

16. Hoffmann A, Kreuzberger S and Hinrichsen G. Influence of thermal degradation on tensile strength and Young's modulus of poly(hydroxybutyrate). Polymer Bulletin. 1994; 33(3):355359. http://dx.doi.org/10.1007/BF00314274.

17. El-Hadi A, Schnabel R, Straube E, M"uller G and Henning S. Correlation between degree of crystallinity, morphology, glass temperature, mechanical properties and biodegradation of poly (3-hydroxyalkanoate) PHAs and their blends. Polymer Testing. 2002; 21(6):665-674. http://dx.doi.org/10.1016/S01429418(01)00142-8.

18. Canetti M and Bertini F. Supermolecular structure and thermal properties of poly(ethyleneterephthalate)/lignin composites. Composites Science and Technology. 2007; 67(15-16):31513157. http://dx.doi.org/10.1016/j.compscitech.2007.04.013.

19. Weihua K, He Y, Asakawa N and Inoue Y. Effect of lignin particles as a nucleating agent on crystallization of poly(3hydroxybutyrate). Journal of Applied Polymer Science. 2004; 94(6):2466-2474. http://dx.doi.org/10.1002/app.21204.

20. Association of Official Analytical Chemists - AOAC. Official Methods of Analysis of Association of Official Analytical Chemists 
International. In: Hortiwis W, editor. 17th ed. Arlington: AOAC; 2000.

21. Pachekoski WM, Agnelli JAM and Belem LP. Thermal, mechanical and morphological properties of poly(hydroxybutyrate) and polypropylene blends after processing. Materials Research. 2009; 12(2):159-164. http://dx.doi.org/10.1590/S151614392009000200008 .

22. American Society for Testing and Materials - ASTM. ASTM 638-03: standard test method for tensile properties of plastics. West Conshohocken; 2001.

23. American Society for Testing and Materials - ASTM. ASTM D256-05: standard test methods for determining the izod pendulum impact for plastics. West Conshohocken; 2001.

24. American Society for Testing and Materials - ASTM. ASTM D638-03: standard test method for tensile properties of plastics. West Conshohocken; 2003.

25. American Society for Testing and Materials - ASTM. ASTM D256-05: standard test methods for determining the izod pendulum impact for plastics. West Conshohocken; 2005.

26. Tonoli GHD, Teixeira EM, Corrêa AC, Marconcini JM, Caixeta LA, Pereira-da-Silva MA, et al. Cellulose micro/nanofibres from Eucalyptus kraft pulp: preparation and properties. Carbohydrate Polymers. 2012; 89(1):80-88. http://dx.doi.org/10.1016/j. carbpol.2012.02.052. PMid:24750607.

27. Thiré RMSM, Arruda LC and Barreto LS. Morphology and thermal properties of poly(3-hydroxybutyrate-co-3hydroxyvalerate)/ attapulgite nanocomposites. Materials Research. 2011; 14(3):340344. http://dx.doi.org/10.1590/S1516-14392011005000046.

28. American Society for Testing and Materials - ASTM. ASTM D570-98: standard test method for water absorption of plastics. West Conshohocken; 1998.

29. Melo JDD, Carvalho LFM, Medeiros AM, Souto CRO and Paskocimas CA. A biodegradable composite material based on polyhydroxybutyrate (PHB) and carnauba fibers. Composites. Part B, Engineering. 2012; 43(7):2827-2835. http://dx.doi.org/10.1016/j.compositesb.2012.04.046.

30. Machado MLC, Pereira NC, de Miranda LF and Terence MC. Estudo das propriedades mecânicas e térmicas do polímero poli-3-hidroxibutirato (PHB) e de compósitos PHB/pó de madeira. Polímeros: Ciência e Tecnologia. 2010; 20(1):65-71.

31. Hong SG, Hsu H-W and Ye M-T. Thermal properties and applications of low molecular weight Polyhydroxybutyrate. Journal of Thermal Analysis and Calorimetry. 2013; 111(2):12431250. http://dx.doi.org/10.1007/s10973-012-2503-3.

32. Prins MJ, Ptasinski KJ and Janssen FJJG. Torrefaction of wood. Part 1. Weight loss kinetics. Journal of Analytical and Applied Pyrolysis. 2006; 77(1):28-34. http://dx.doi.org/10.1016/j. jaap.2006.01.002.

33. Pachekoskia WM, Dalmolina C and Agnelli JAM. The Influence of the Industrial processing on the degradation of Poly(hidroxybutyrate) - PHB. Materials Research. 2013; 16(2):327-332.

34. Slade L and Levine H. The glassy state phenomenon in food molecules. In: Blanshard JMV and Lillford PJ, editors. The glassy state in foods. Nottingham: Nottingham University Press; 1992. p. 35-101.
35. Reis KC, Pereira J, Smith AC, Carvalho CWP, Wellner N and Yakimets I. Characterization of polyhydroxybutyratehydroxyvalerate (PHB-HV)/maize starch blend films. Journal of Food Engineering. 2008; 89(4):361-369. http://dx.doi. org/10.1016/j.jfoodeng.2008.04.022.

36. Ghaffar A. Development material based on poly(3-hydroxybutyrate) $P H B$. [Dissertation]. Saale: Martin-Luther-Universität HalleWittenberg; 2002.

37. Murayama T. Dynamic mechanical analysis of polymeric material. New York: Elsevier; 1978. v. 1. 231 p.

38. Pinto CES, Arizaga GGC, Wypych F, Ramos LP and Satyanarayana KG. Studies of the effect of molding pressure and incorporation of sugarcane bagasse fibers on the structure and properties of poly (hydroxy butyrate). Composites. Part A, Applied Science and Manufacturing. 2009; 40(5):573-582. http://dx.doi.org/10.1016/j.compositesa.2009.02.004.

39. Jiménez G, Ogata N, Kawai H and Ogihara T. Structure and thermal/mechanical properties of poly (-caprolactone)clay blend. Journal of Applied Polymer Science. 1997; 64(11):2211-2220. http://dx.doi.org/10.1002/(SICI)10974628(19970613)64:11<2211::AID-APP17>3.0.CO;2-6.

40. Di Maio E, Iannace S, Sorrentino L and Nicolais L. Isothermal crystallization in PCL/clay nanocomposites investigated with thermal and rheometric methods. Polymer. 2004; 45(26):88938900. http://dx.doi.org/10.1016/j.polymer.2004.10.037.

41. Javadi A, Srithep Y, Pilla S, Lee J, Gong S and Turng LS. Processing and characterization of solid and microcellular phbv/ coir fiber composites. Materials Science and Engineering C. 2010; 30(5):749-757. http://dx.doi.org/10.1016/j.msec.2010.03.008.

42. Botana A, Mollo M, Eisenberg P and Torres Sanchez RM. Effect of modified montmorillonite on biodegradable PHB nanocomposites. Applied Clay Science. 2010; 47(3-4):263-270. http://dx.doi.org/10.1016/j.clay.2009.11.001.

43. Srubar WV 3rd, Pilla S, Wright ZC, Ryan CA, Greene JP, Frank CW, et al. Mechanisms and impact of fiber-matrix compatibilization techniques on the material characterization of PHBV/oak wood flour engineered biobased composites. Composites Science and Technology. 2012; 72(6):708-715. http://dx.doi.org/10.1016/j.compscitech.2012.01.021.

44. Avella M, Bogoeva-Gaceva G, Buzõarovska A, Emanuela Errico M, Gentile G and Grozdanov A. Poly(3-hydroxybutyrate-co-3hydroxyvalerate)-based biocomposites reinforced with Kenaf fibers. Journal of Applied Polymer Science. 2007; 104(5):31923200. http://dx.doi.org/10.1002/app.26057.

45. Garkhail SK, Heijenrath RWH and Peijs T. Mechanical properties of natural fiber- mat-reinforced thermoplastics based on flax fibers and polypropylene. Applied Composite Materials. 2000; 7(5-6):351-372.

46. Barkoula NM, Garkhail SK and Peijs T. Effect pg Compounding and Injection Molding on the Mechanical properties of flax fibers polypropylene composites. Journal of Reinforced Plastics and Composites. 2010; 29(9):1366-1385. http://dx.doi. org/10.1177/0731684409104465.

47. Wong S, Shanks R and Hodzic A. Properties of poly(3hydroxyburic acid) composites with flax fibres modified by plasticizer absorption. Macromolecular Materials and Engineering. 2002; 287(10):647-655. http://dx.doi.org/10.1002/14392054(200210)287:10<647::AID-MAME647>3.0.CO;2-7. 